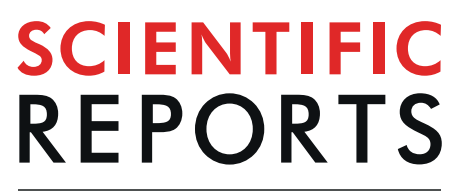

natureresearch

\title{
Structure of the agonist 12-HHT in its BLT2 receptor-bound state
}

\author{
Fabrice Giusti ${ }^{1,2}$, Marina Casiraghi ${ }^{1,3}$, Elodie Point ${ }^{1}$, Marjorie Damian ${ }^{4}$, Jutta Rieger ${ }^{5}$, \\ Christel Le Bon ${ }^{1}$, Alexandre Pozza ${ }^{1}$, Karine Moncoq ${ }^{1}$, Jean-Louis Banères ${ }^{4}$ \& \\ Laurent J. Catoire ${ }^{1 *}$
}

G Protein-Coupled receptors represent the main communicating pathway for signals from the outside to the inside of most of eukaryotic cells. They define the largest family of integral membrane receptors at the surface of the cells and constitute the main target of the current drugs on the market. The low affinity leukotriene receptor BLT2 is a receptor involved in pro- and anti-inflammatory pathways and can be activated by various unsaturated fatty acid compounds. We present here the NMR structure of the agonist 12-HHT in its BLT2-bound state and a model of interaction of the ligand with the receptor based on a conformational homology modeling associated with docking simulations. Put into perspective with the data obtained with leukotriene B4, our results illuminate the ligand selectivity of BLT2 and may help define new molecules to modulate the activity of this receptor.

G protein-coupled receptors (GPCRs) are integral membrane proteins that allow the signal transduction from the outside to the inside of most of eukaryotic cells ${ }^{1}$. These receptors consist in a large family of proteins whose activities can be related to various ligands, from small organic compounds like neurotransmitters or hormones, to lipids, peptides or proteins. As such, they are key players in many biological processes and represent one of the most common target of clinical drugs ${ }^{2,3}$. Signal transduction through GPCRs concentrates a cascade of biological events that, if we exclude the constitutive activity, starts with the interaction of an extracellular signaling molecule with these membrane proteins, and triggers, at the end, a cellular response. This binding of a ligand onto its cognate receptor represents a fundamental stage in the activation process. To get a picture of this interaction at the atomic scale is not trivial as the number of high-quality crystals in the presence of natural agonists is limited ${ }^{4-6}$.

In addition to X-ray diffraction and cryo-electronic microscopy (cryo-EM) ${ }^{7-10}$, NMR spectroscopy can bring important information regarding conformational and energy landscapes ${ }^{11-16}$ or, as shown here, on the structure of natural GPCR ligands in their receptor bound-states. This technique can indeed provide a detailed description of the ligand in its bound-state, at physiological temperature and with a native protein ${ }^{17-25}$. Especially with very flexible ligands, like those described in this study, NMR data can constitute the basic input to subsequent X-rayor cryo-EM-based molecular modeling of ligand/GPCR complexes.

The leukotriene receptors $1^{26}$ (BLT1) and $2^{27-30}$ (BLT2) are cell surface GPCRs that share 45\% amino acid sequence identity in human and are involved in pro- and anti-inflammatory pathways ${ }^{31-34}$. They were initially named high (BLT1) and low leukotriene B4 (LTB4) (BLT2) receptors as the equilibrium dissociation constant $\left(\mathrm{K}_{d}\right)$ values of LTB4 in the presence of membrane fractions transfected by either BLT1 or BLT2 is 20-fold weaker in the case of BLT2 compared to BLT1 transfected HEK 293 cells (i.e. $\sim 1 \mathrm{nM}$ and $20 \mathrm{nM}$ for BLT1 and BLT2, respectively $)^{30}$. BLT1 receptor is essentially expressed in leukocytes and lymphocytes and is mainly activated by the LTB $4^{35}$ which is a strong potent lipid inflammatory mediator. By contrast, BLT2 is expressed in various tissues and has been shown to bind to different arachidonic acid metabolites with moderate affinities, including LTB4 ${ }^{36}$.

In 2008, the heptadecanoid 12S-hydroxyheptadeca-5Z,8E,10E-trienoic acid ${ }^{37}$ (12-HHT) was suggested to be the endogenous ligand of BLT2 ${ }^{38}$. In membrane fractions of Chinese Hamster Ovary cells (CHO) transfected by BLT2, the half maximal inhibitory concentration (IC50) and the half maximal effective concentration (EC50)

${ }^{1}$ Laboratoire de Biologie Physico-Chimique des Protéines Membranaires, UMR 7099, CNRS/Université de Paris, Institut de Biologie Physico-Chimique (FRC 550), 13 rue Pierre et Marie Curie, F-75005, Paris, France. ${ }^{2}$ Present address: Institut de Chimie Séparative de Marcoule, ICSM UMR 5257, Site de Marcoule, Bâtiment 426, BP 17171, F-30207, Bagnols sur Cèze Cedex, France. ${ }^{3}$ Present address: Department of Molecular and Cellular Physiology, Stanford University School of Medicine, 279 Campus Drive, 94305, Stanford California, USA. ${ }^{4}$ Institut des Biomolécules Max Mousseron (IBMM), UMR 5247 CNRS, Université Montpellier, ENSCM, , 15 av. Charles Flahault, 34093, Montpellier, France. ${ }^{5}$ Institut Parisien de Chimie Moléculaire, Sorbonne Université, CNRS, UMR 8232, Equipe Chimie des Polymères, 4 place Jussieu, 75252, Paris Cedex, 05, France. *email: laurent.catoire@ibpc.fr 
values of 12-HHT are about one order of magnitude lower than LTB4 while it does not bind to BLT1 $1^{38}$. The main source of $12-\mathrm{HHT}$ comes as a reaction product of the conversion of prostaglandin $\mathrm{H} 2$ to thromboxane A2 and malonyldialdehyde by the thromboxane synthase ${ }^{39}$. Recent studies highlighted an important activity of the 12-HHT/BLT2 axis in various pathologies, including inflammatory and allergic diseases ${ }^{38,40-42}$, wound healing ${ }^{43}$ and cancers ${ }^{44-48}$.

Here, we determined by NMR spectroscopy the three-dimensional (3D) structure of the agonist 12-HHT associated with human BLT2. As observed with the LTB4 in the presence of the same receptor ${ }^{18}, 12-\mathrm{HHT}$ adopts also a non-extended conformation. We propose also a tentative model of interaction of 12-HHT with BLT2 based on X-ray crystal structure conformational homology modeling and docking simulations, with the support of unequivocal experimental data.

\section{Methods}

Sample preparations. The heptdadecanoid 12-HHT and the eicosanoid LTB4 were obtained from Cayman Chemical, Ann Arbor, USA, as ethanolic solutions. The ethanol was extensively evaporated under vacuum. Then the eicosanoids in excess respectively to the receptor were directly dissolved by the NMR sample containing the receptor associated with perDAPol in a $100 \%-\mathrm{D}_{2} \mathrm{O}$ solution $(20 \mathrm{mM}$ Tris/ $\mathrm{HCl}$ buffer $\mathrm{pH} 8,100 \mathrm{mM} \mathrm{NaCl})$ at final concentrations of $\sim 120$ and $\sim 140 \mu \mathrm{M}$ of $12-\mathrm{HHT}$ and LTB4, respectively. The receptor concentration was $\sim 15$ $\mu \mathrm{M}$ which gives rise to ligand/BLT2 molar ratio of 8 and $\sim 9$ for 12-HHT/BLT2 and LTB4/BLT2. Considering a percentage of properly folded receptor ranging from 50 to $70 \%{ }^{49}$, this means an effective ligand/receptor ratios of $15 \pm 4$. Synthesis of perDAPol was performed as already described ${ }^{50}$ and the overexpression, purification and folding of perdeuterated human BLT2 receptor is detailed in Catoire et al. ${ }^{18}$.

Site-directed mutagenesis. All mutations were introduced in the wild-type BLT2 receptor by PCR-mediated mutagenesis using the QuickChange multisite-directed mutagenesis kit (Stratagene) and the wild-type BLT2 construct as a template. Mutations were confirmed by nucleotide sequencing.

Ligand binding assays. Agonist binding to the isolated BLT2 receptor was monitored through ligand-dependent receptor-catalyzed G protein activation, as described in Arcemisbéhère et al. (two different types of experiments were carried out to demonstrate 2010). $G_{\alpha i 2}$ and $G_{\beta 1 \gamma 2}$ were prepared as previously described $^{51}$. Briefly, agonist-dependent functional coupling of the purified receptor to $\mathrm{G}_{\alpha i 2 \beta 1 / 2}$ was assessed through the rate of GTP $\gamma$ binding at increasing agonist concentrations determined by monitoring the relative increase in the intrinsic fluorescence $\left(\lambda_{\text {excitation }}=300 \mathrm{~nm}, \lambda_{\text {emission }}=345 \mathrm{~nm}\right)$ of $\mathrm{G}_{\alpha i 2}(200 \mathrm{nM}$ of purified G protein) in the presence of BLT2 $(20 \mathrm{nM})$ in buffer containing $10 \mathrm{mM} \mathrm{MOPS}, \mathrm{pH} 7.2,130 \mathrm{mM} \mathrm{NaCl}$, and $2 \mathrm{mM}$ $\mathrm{MgCl}_{2}$ at $15^{\circ} \mathrm{C}$ after the addition of $10 \mu \mathrm{M} \mathrm{GTP} \gamma \mathrm{S}$. The data were normalized to the fluorescence maximum obtained in the presence of saturating concentrations in 12-HHT $(10 \mu \mathrm{M})$.

NMR spectroscopy. All NMR experiments were conducted at $25^{\circ} \mathrm{C}$ and $700 \mathrm{MHz}$ on a Bruker Avance spectrometer equipped with a cryoprobe. The dipolar interactions were detected and collected in a transferred mode, i.e. in the presence of an excess of ligand over the receptor thanks to a electrostatically-driven fast association and the perdeuteration of the receptor which allow detection of transferred cross-relaxation for GPCR ligands with equilibrium dissociation constants in the high-to-low nanomolar range (see the theoretical and experimental demonstration in Catoire et al ${ }^{19}$ ). The following parameters were used for 2D NOESY experiments: 4 different mixing times $\left(\tau_{m}=0.1 \mathrm{~s}, 0.2 \mathrm{~s}, 0.35 \mathrm{~s}, 0.5 \mathrm{~s}\right.$ in the study of $12-\mathrm{HHT}$ and $\tau_{m}=0.05 \mathrm{~s}, 0.1 \mathrm{~s}, 0.2 \mathrm{~s}, 0.5 \mathrm{~s}$ with the LTB4); data size $=256\left(t_{1}\right) \times 8,192\left(t_{2}\right)$ complex points, $t_{1_{\max }}=36.5 \mathrm{~ms}, t_{2}=585 \mathrm{~ms}, 128$ acquisitions per increment, experiment time $=11.5$ to 15.7 hours. Water suppression was conducted by using an excitation sculpting scheme with gradients ${ }^{52}$. Prior to Fourier Transform, the time domain signal was apodized by a square cosine in both dimensions. No baseline correction was applied. ${ }^{1} \mathrm{H}$ chemical shifts are referenced to $\mathrm{H}_{2} \mathrm{O}$ (calibrated at $4.7 \mathrm{ppm}$ at $25^{\circ} \mathrm{C}$ ). Chemical shift assignments are based on COSY spectra from Catoire et al..$^{18}$ and ${ }^{19}$. Data processing and analyzing were performed with TOPSPIN software.

Structure calculations. $\quad 12-\mathrm{HHT}$ and LTB4 $\mathrm{pdb}$ files were produced with PRODRG ${ }^{53}$. Parameter and topology files were generated with XPLO2D (version 3.3.2) 54 $^{5}$. Structure calculations were performed with the program ARIA (Ambiguous Restraints for Iterative Assignment) (version 2.3) ${ }^{55}$ associated with CNS ${ }^{56}$ using standard protocols. For each ligand, calculations were based on four sets of NOE data corresponding to four distinct $\tau_{m}$ (see Tables S1-S4 and S6-S9 for 12-HHT and LTB4, respectively). A full relaxation matrix treatment of NOE data has been applied in ARIA/CNS to take into account indirect ${ }^{1} \mathrm{H}-{ }^{1} \mathrm{H}$ cross-relaxation pathways ${ }^{57,58}$. In the case of 12-HHT, only dipolar contacts involving $\mathrm{H} 2, \mathrm{H} 3$, and $\mathrm{H} 17$ with the other ligand protons were taken into account as these dipolar restraints display the lowest level of non-specific binding contribution to the peak volumes (unstructured parts in the ligand in the absence of the receptor). For LTB4, only protons at both ends interacting with the other protons in the ligands, i.e. $\mathrm{H} 2, \mathrm{H} 3, \mathrm{H} 4$ and $\mathrm{H} 16, \mathrm{H} 17, \mathrm{H} 18, \mathrm{H} 19$ and $\mathrm{H} 20$, were taken into account in the structure calculation. The structures were drawn using the software PyMOL.

Homology modelling of receptors and ligand docking simulations. Homology modelling of BLT2

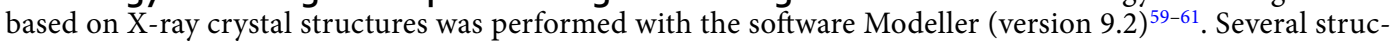
tures were tested, including the two mentionned in this manuscript: BLT1 (pdb code $5 \times 33^{62}$ ) and $\beta 2 \mathrm{AR}$ ( $\mathrm{pdb}$ code $\left.3 \mathrm{p} \mathrm{g}^{4}\right)$. Docking simulations of $12-\mathrm{HHT}$ in human BLT2 receptor were subsequently performed with HADDOCK (version 2.2) taking as active residues $\mathrm{S} 174^{E C L 2}$ and $\mathrm{R} 270^{7.35}$ only. 


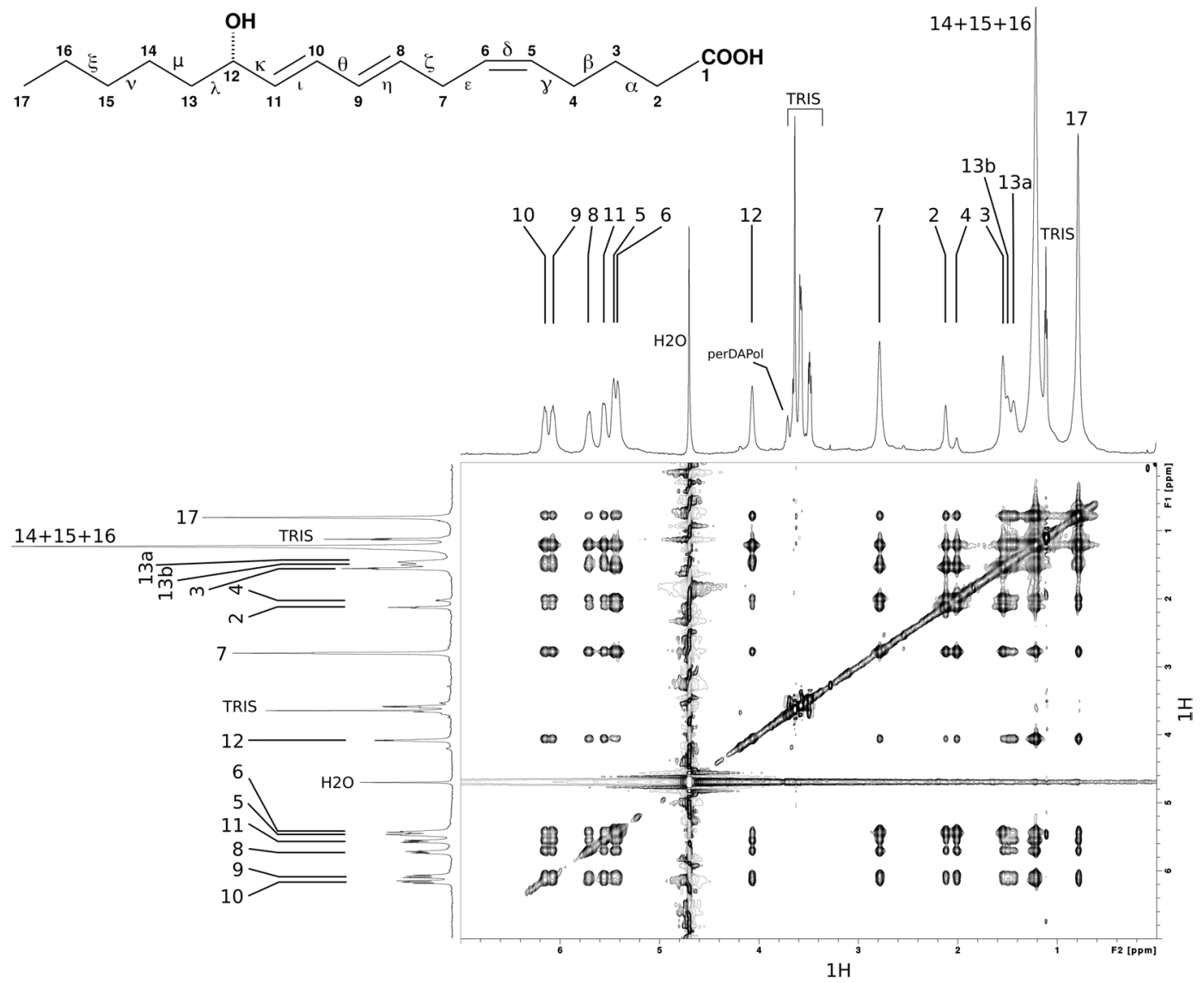

Figure 1. Dipolar interactions in the $12-\mathrm{HHT} / \mathrm{u}-{ }^{2} \mathrm{H}-\mathrm{wtBLT} 2 /$ perDAPol sample observed in a $2 \mathrm{D}$ NOESY $\operatorname{spectrum}\left(\tau_{m}=0.5 \mathrm{~s}, \nu_{H}=700 \mathrm{MHz}, 25^{\circ} \mathrm{C},[12-\mathrm{HHT}]=120 \mu \mathrm{M},[\mathrm{BLT} 2]=15 \mu \mathrm{M}\right)$. The corresponding 1D ${ }^{1} \mathrm{H}$ spectrum is shown above the $2 \mathrm{D}$ spectrum and a $1 \mathrm{D}$ spectrum of free $12-\mathrm{HHT}$ in solution is displayed on the left side. Numbers refer to the protons annotated on the 12-HHT chemical structure indicated above the spectrum.

\section{Results}

Structure of 12-HHT associated with BLT2 receptor. The NMR study of 12-HHT in its receptor-bound state was realized in vitro in a detergent-free solution ${ }^{63}$ following a method that has been already applied with the LTB4 in the presence of the same receptor ${ }^{18,19}$. Briefly, the heterologous human BLT2 receptor was expressed in Escherichia coli in a $100 \%-\mathrm{D}_{2} \mathrm{O}$ solution to inclusion bodies ${ }^{64,65}$ and was subsequently folded to its native state using amphipols ${ }^{49,66}$. The NMR structure of $12-\mathrm{HHT}$ is based on the detection of dipolar interactions in the ligand through two-dimensional homonuclear ${ }^{1} \mathrm{H}$ Nuclear Overhauser Effect SpectroscopY (NOESY) experiments ${ }^{67}$. The dipolar interactions were collected in a transferred mode in the presence of an excess of ligand over the receptor. Indeed, it has been demonstrated that solution-state NMR can detect transferred NOEs even with equilibrium dissociation constants below the micromolar range because of $i$ ) an inherent ultra-fast diffusive association of these negatively charged agonists onto a highly positively charged extracellular surface, and $i i)$ the slowing down of the ${ }^{1} \mathrm{H}-{ }^{1} \mathrm{H}$ cross-relaxation thanks to receptor perdeuteration ${ }^{19}$. In order to improve the number and quality of intra-ligand ${ }^{1} \mathrm{H}-{ }^{1} \mathrm{H}$ dipolar contacts, BLT2 was maintained soluble and stable in solution associated with a perdeuterated amphipol named perDAPol ${ }^{50}$. Compared to the pioneer study of LTB4 associated with BLT2, perDAPol offered the possibility to observe intra-aliphatic ${ }^{1} \mathrm{H}$ dipolar interactions in the ligand (Fig. 1) (for a comparative observation, see Fig. S1).

In the presence of BLT2 associated with either amphipols or nanodiscs, 12-HHT displays a higher proportion of non-specific binding compared to LTB4 (see for instance Supplementary Fig. S8 in Casiraghi et al. ${ }^{11}$ ). This is presumably due to a more hydrophobic character which favours the interaction of the ligand with the belt of surfactant molecules or lipids ${ }^{11}$. To correctly assess the presence of specific intra-ligand dipolar interactions, the NMR collection of constraints was based on a rigorous observation of specific intra-ligand ${ }^{1} \mathrm{H}-{ }^{1} \mathrm{H}$ dipolar interactions in the bound-state in the presence of a perdeuterated receptor ${ }^{18,19}$. In the absence of the receptor, i.e. in the presence of perDAPol only, we observed the absence and/or the presence of weak ${ }^{1} \mathrm{H}-{ }^{1} \mathrm{H}$ dipolar interactions between aliphatic protons located at both ends, i.e. from protons $\mathrm{H} 2$ to $\mathrm{H} 4$ on one side, and from $\mathrm{H} 13$ to $\mathrm{H} 17$ on the other side, with the other ${ }^{1} \mathrm{H}$ in the ligand (Figs. S2 and S3). This indicates that both ligand ends are not structured in the absence of the receptor. Moreover, non-specific ${ }^{1} \mathrm{H}$ to ${ }^{1} \mathrm{H}$ interactions between the ligand and the surfactant can be observed in a 2D NOESY spectrum (e.g. the regions squared with a green dashed line in Fig. S2). 
The NMR data corresponding to only specific interactions were collected at four different Nuclear Overhauser Effect (NOE) mixing times $\tau_{m}$, i.e. 0.1, 0.2, 0.35 and $0.5 \mathrm{~s}$ and integrated for structure calculations (Tables S1-S4). Dipolar interactions between $\mathrm{H} 2, \mathrm{H} 3$ and $\mathrm{H} 17$ with the other protons in the ligand were actually enough to obtain a converged set of structures (Tables S1-S4 and Fig. S4). This set of low energy conformers of 12-HHT in its BLT2 bound-state is depicted in Fig. 2 (with associated structural statistics gathered in Table 1). In order to describe any conformational rearrangement of the structure of the ligand upon binding to its receptor, a structure analysis of 12-HHT free in solution was performed (Table S5) and is also indicated in Fig. 2. As expected, in the free state, structure calculation indicates that both aliphatic ends of the molecule are flexible with the coexistence of various rotamers. However, compared to calculations conducted without any experimental restraints, 12-HHT free in solution adopts preferential conformations at the pentyl-end (carbon atoms 13 to 17), precluding any extended conformation along the axis defined by the unsaturated bonds. Compared to the free-state in solution, the ligand describes a well-constrained conformation in the presence of the receptor. In particular, both ends, the carboxyl-end (1-carboxy-pent-4-ene-5-yl chain, carbons $\mathrm{C} 1$ to C6) and the pentyl-end (carbon atoms 13 to 17), adopt a unique orientation respectively to the rigid core of the molecule (dihedral angles $\zeta$ and $\kappa$ in Fig. 2).

Docking model of 12-HHT associated with BLT2 receptor. The set of 20 low energy conformers depicted in Fig. 2 was further integrated in a model of the BLT2 receptor to perform docking simulations using the software HADDOCK ${ }^{68,69}$. The model of the BLT2 receptor using Modeller ${ }^{59-61}$ was based on the active state of the $\beta 2$ adrenergic receptor ( $\beta 2 \mathrm{AR}$ ) ( $\mathrm{pdb}$ code $\left.3 \mathrm{p} 0 \mathrm{~g}^{4}\right)$ in spite a structure of BLT1 associated with an inverse agonist being available in the protein databank ( $\mathrm{pdb}$ code $5 \times 33^{62}$ ). Using BLT1 crystal structure in an inactive state does not allow the ligand 12-HHT to interact with important amino acids in the BLT2 receptor that have been identified by site-directed mutagenesis experiments associated with ligand binding assays (Fig. 3A and Table 2). In particular, residue S174 in the extra-cellular loop 2 (ECL2) BLT1-based BLT2 model is located too far from the top of the ligand orthosteric pocket as the loop is in an open-lid conformation in the inactive state (Fig. S5). To reproduce contacts between the ligand and the receptor based on our binding studies, a conformational homology model was built. In addition, the identity in amino acid sequence between BLT1 and BLT2 is only $45 \%$, which is mostly in the 7TM. Docking simulations were performed for each of the 20 NMR conformers based on two active residues identified by mutagenesis, S174 and R270 (Fig. 3A). Simulations with HADDOCK were started with $12-\mathrm{HHT}$ NMR conformers well away from the orthosteric site of $\beta 2 \mathrm{AR}$-active-based BLT2 model, i.e. not partly positioned in the orthosteric site.

All these simulations gave rise to a single cluster or a predominant cluster of structures representing 97 to $100 \%$ of the water-refined models generated by HADDOCK. The simulations proposed various possible orientations of the ligand in the orthosteric pocket, but only one orientation depicted in Fig. 4 is compatible with site-directed mutagenesis experiments associated with ligand binding assays (Fig. 3A and Table 2) with a particular focus on the two residues that establish hydrogen bonds with 12-HHT, i.e. S174 ${ }^{E C L 2}$ and R270 7.35 (superscripts indicate residue numbering following the Ballesteros-Weinstein nomenclature ${ }^{70}$ ). Indeed, that orientation shows an excellent agreement with these two single mutations, i.e. $S 174^{E C L 2} \mathrm{~A}$ and $\mathrm{R} 270^{7.35} \mathrm{~A}$, with EC50 values shifted from $21 \mathrm{nM}$ (wild-type) to $295 \mathrm{nM}$ for S174 ${ }^{E C L 2} \mathrm{~A}$ and $235 \mathrm{nM}$ for R270 $27.35 \mathrm{~A}$. In that position, $\mathrm{S} 174^{E C L 2}$ establishes hydrogen bonds with the carboxylate group of 12-HHT and R270 7.35 interacts with the hydroxyl moiety of the ligand through hydrogen bonds as well (Fig. 4). A similar position of the ligand that came out from the simulations involves an additional hydrogen bond between the hydroxyl group of the ligand and Q267 ${ }^{7.32}$, but as no significant change in ligand binding could be observed by introducing the mutation Q267.32 A (Fig. 3A and Table 2), that orientation was discarded.

The model of the interaction of 12-HHT NMR structure with a model of BLT2 based on an active conformation of $\beta 2 \mathrm{AR}$ displays interactions with five secondary elements in the receptor: 4 helices (II, III, VI and VII), which delineate the contours of the orthosteric pocket, and one extra-cellular loop (ECL2) which plays a role of lid above the ligand pocket (Fig. 4). In addition to the two amino acids that establish hydrogen bonds with the ligand $\left(S 174^{E C L 2}\right.$ and $\left.\mathrm{R} 270^{7.35}\right), 10$ other amino acids located at a distance $\leq 4 \AA$ from the ligand ( 20 amino acids located at a distance $\leq 5 \AA$ depicted in Fig. 4) show various weak interactions, including $\mathrm{CH}$-to- $\pi, \mathrm{CH}$-to-O, $\mathrm{NH}$-to- $\pi$, S-to- $\mathrm{CH}$ or $\mathrm{N}$-to- $\mathrm{CH}$ proximities. The model of interaction depicted in Fig. 4 is also in accordance with some other neutral mutations that have been tested: first, residues that are important for LTB4 binding to BLT1. $\mathrm{R} 160^{4.64}$, which is highly conserved in both BLT1 and BLT2 receptors (Fig. S6), has been identified to be crucial for LTB4 binding on BLT1 (residue R156 in BLT1) by potentially making a direct hydrogen bond with the carboxylate head group ${ }^{71}$. Mutation of this residue to alanine results in a complete loss of LTB4 binding ${ }^{71}$. Accordingly to our model, in which R160 $0^{4.64}$ is located very far from 12-HHT (Fig. S7), R160 ${ }^{4.64}$ A mutant has no effect on 12-HHT binding (Fig. 3A and Table 2). In the same way, the E185A mutation did not significantly affect 12-HHT binding (Fig. 3A) whereas mutating this residue had a noticeable impact on LTB4 binding onto BLT1 ${ }^{71}$. Second, some neutral mutations have been conducted. Just beside S174 ${ }^{E C L 2}$ in ECL2, but not establishing any interaction with the ligand, $\mathrm{P} 175^{E C L 2}$ and $\mathrm{H} 177^{E C L 2}$, which mutations to alanine do not display a significant impact on ligand binding compared to the wild-type receptor. Another residue in ECL2, which could possibly interact with the carboxyl function of the ligand, R166 ${ }^{E C L 2}$, and an additional neutral mutation close to $\mathrm{R} 270^{7.35}$, T274 $4^{7.39} \mathrm{~A}$, do not impact receptor ligand properties (Fig. 3A and Table 2) in accordance with our model.

Comparison of 12-HHT and LTB4 structures in their BLT2-bound states. We present also in this study a new set of converged structures of LTB4 associated with BLT2 in order to compare the bound structures of 12-HHT and LTB4 obtained under identical conditions and procedures. Compared to the first calculation published in $2010^{18}$, NMR data were collected at $700 \mathrm{MHz}$ with a receptor associated with perDAPol ${ }^{50}$ instead of DAPol and by using a softer methodology to remove the ${ }^{1} \mathrm{H}$ signal of $\mathrm{H}_{2} \mathrm{O}$ to not affect signal intensities from the ligand (see Material and Methods). As observed with 12-HHT, in the absence of the receptor, both ends of the 

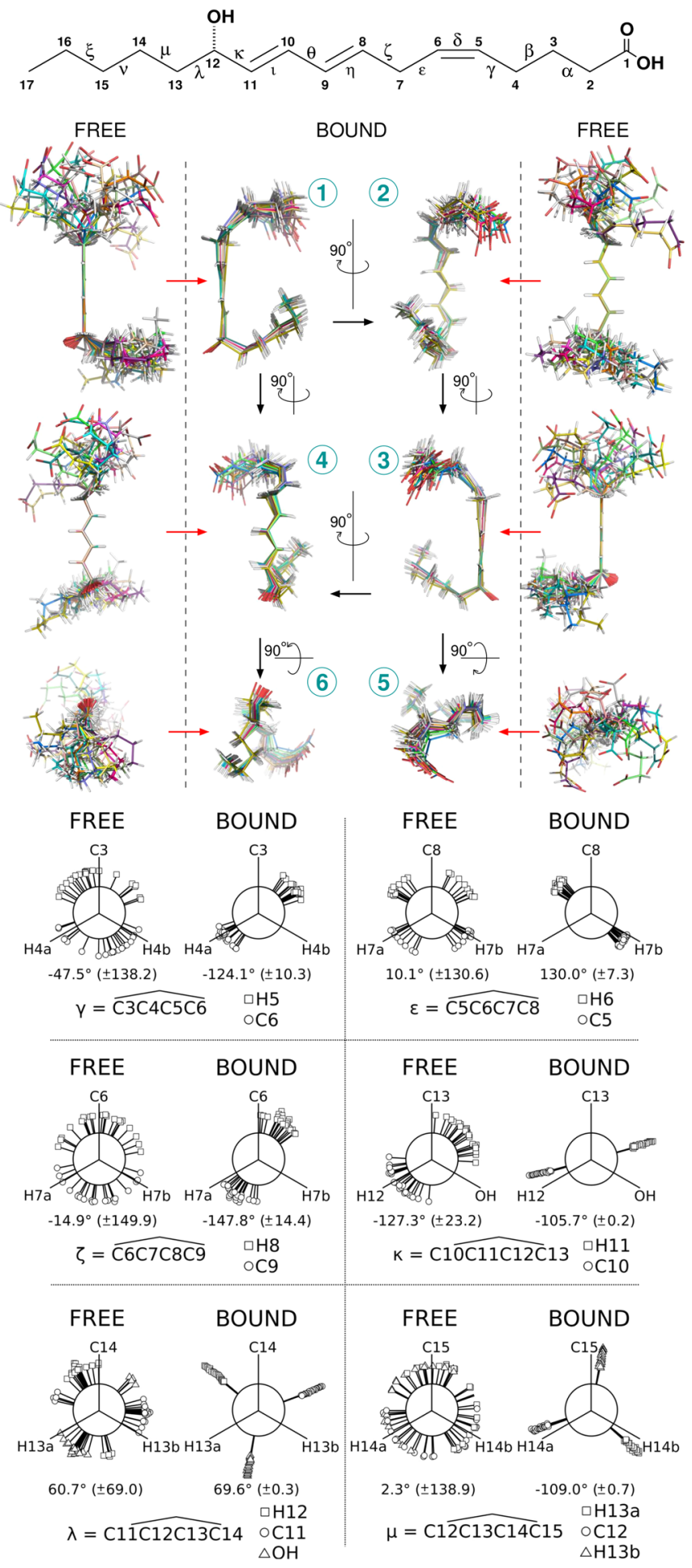

Figure 2. Three-dimensional structure of $12-\mathrm{HHT}$ free in solution or bound to BLT2. (Top) Primary chemical structure of 12-HHT. The carbons are numbered from the carboxyl function to the methyl group. Greek letters refer to some dihedral angles displayed at the bottom of the figure. (Middle) Six different views of two ensembles of 20 energy-minimized conformers (in white, hydrogen atoms; in red, oxygen atoms; carbon atoms are assigned a different color for each conformer). The red arrows indicate the transition from the free to the bound state for a same orientation of the diene located at the center of the molecule (carbons C8 to C11). (Bottom) Comparison of dihedral angles between the free and the bound states for the set of 20 conformers displayed above.

ligand are not structured, based on the observation of intra-ligand ${ }^{1} \mathrm{H}-$ to- $-{ }^{1} \mathrm{H}$ dipolar interactions (Fig. S8). Calculation based on NMR data collected in the presence of BLT2 gives rise to a folded structure (Fig. S9 and Table S10) similar to the previous published structure ${ }^{18}$, but with an orientation of the carboxyl-end (carbons 1 to 5) 


\begin{tabular}{|c|c|c|c|}
\hline \multirow{2}{*}{\multicolumn{2}{|c|}{$\begin{array}{l}\text { NOE-based distance restraints } \\
\text { Inter-protons } i, j \text { at } \tau_{m}=0.1 \mathrm{~s}\end{array}$}} & \multicolumn{2}{|c|}{ NOE-based distance restraints } \\
\hline & & \multicolumn{2}{|c|}{ Inter-protons $i, j$ at $\tau_{m}=0.2 \mathrm{~s}$} \\
\hline$|i-j|=1$ & 3 & $|i-j|=1$ & 3 \\
\hline$|i-j|=2$ & 2 & $|i-j|=2$ & 3 \\
\hline$|i-j|=2.5$ & 1 & $|i-j|=2.5$ & 1 \\
\hline$|i-j|=3$ & 3 & $|i-j|=3$ & 2 \\
\hline$|i-j|=4$ & 4 & $|i-j|=4$ & 3 \\
\hline$|i-j|=5$ & 3 & $|i-j|=5$ & 4 \\
\hline$|i-j|=6$ & 3 & $|i-j|=6$ & 3 \\
\hline$|i-j|=7$ & 3 & $|i-j|=7$ & 3 \\
\hline$|i-j|=8$ & 2 & $|i-j|=8$ & 3 \\
\hline$|i-j|=9$ & 1 & $|i-j|=9$ & 2 \\
\hline$|i-j|=10$ & 1 & $|i-j|=10$ & 2 \\
\hline$|i-j|=11$ & 2 & $|i-j|=11$ & 2 \\
\hline$|i-j|=12$ & 1 & $|i-j|=12$ & 2 \\
\hline$|i-j|=13$ & 2 & $|i-j|=13$ & 2 \\
\hline$|i-j|=15$ & 1 & $|i-j|=15$ & 1 \\
\hline Total & 32 & Total & 36 \\
\hline \multicolumn{2}{|c|}{ Inter-protons $i, j$ at $\tau_{m}=0.35 \mathrm{~s}$} & \multicolumn{2}{|c|}{ Inter-protons $i, j$ at $\tau_{m}=0.5 \mathrm{~s}$} \\
\hline$|i-j|=1$ & 3 & $|i-j|=1$ & 2 \\
\hline$|i-j|=2$ & 3 & $|i-j|=2$ & 1 \\
\hline$|i-j|=2.5$ & 1 & $|i-j|=2.5$ & 1 \\
\hline$|i-j|=3$ & 2 & $|i-j|=3$ & 1 \\
\hline$|i-j|=4$ & 4 & $|i-j|=4$ & 3 \\
\hline$|i-j|=5$ & 4 & $|i-j|=5$ & 3 \\
\hline$|i-j|=6$ & 3 & $|i-j|=6$ & 2 \\
\hline$|i-j|=7$ & 3 & $|i-j|=6.5$ & 1 \\
\hline$|i-j|=8$ & 3 & $|i-j|=7$ & 2 \\
\hline$|i-j|=9$ & 2 & $|i-j|=8$ & 2 \\
\hline$|i-j|=10$ & 2 & $|i-j|=9$ & 3 \\
\hline$|i-j|=11$ & 2 & $|i-j|=10$ & 2 \\
\hline$|i-j|=12$ & 1 & $|i-j|=11$ & 1 \\
\hline$|i-j|=13$ & 2 & $|i-j|=12$ & 2 \\
\hline$|i-j|=14$ & 1 & $|i-j|=13$ & 2 \\
\hline \multirow[t]{2}{*}{$|i-j|=15$} & 1 & $|i-j|=14$ & 1 \\
\hline & & $|i-j|=15$ & 1 \\
\hline Total & 37 & Total & 30 \\
\hline \multicolumn{4}{|c|}{ Structural statistics } \\
\hline \multicolumn{2}{|c|}{ Number of NOE violations $>0.5 \AA$} & \multicolumn{2}{|l|}{$1 \pm 0$} \\
\hline \multicolumn{2}{|c|}{ Number of NOE violations $>0.2 \AA$} & \multicolumn{2}{|l|}{$1 \pm 0$} \\
\hline \multicolumn{2}{|c|}{ Number of NOE violations $>0.1 \AA$} & \multicolumn{2}{|l|}{$3.4 \pm 0.49$} \\
\hline \multicolumn{2}{|c|}{ Mean global rms } & \multicolumn{2}{|l|}{$0.22 \pm 0.20(\AA)$} \\
\hline \multicolumn{4}{|c|}{ Deviation from idealized geometry } \\
\hline \multicolumn{2}{|c|}{ Mean rms bond } & \multicolumn{2}{|c|}{$4.8 \times 10^{-3} \pm 5.1 \times 10^{-5}(\AA)$} \\
\hline \multicolumn{2}{|c|}{ Mean rms angle } & \multicolumn{2}{|c|}{$0.78 \pm 5.7 \times 10^{-3}$ (degrees) } \\
\hline Mean rms im & & $2.16 \pm 8.2 \times 10$ & grees) \\
\hline Mean rms dih & & $0.37 \pm 7.0 \times 10$ & grees) \\
\hline Mean energie & $\left.\mathbf{n o l}^{-1}\right)$ & & \\
\hline $\mathrm{E}_{\text {bonds }}$ & & $1.05 \pm 2.2 \times 10$ & \\
\hline $\mathrm{E}_{\text {angles }}$ & & $7.53 \pm 0.11$ & \\
\hline $\mathrm{E}_{\text {impropers }}$ & & $18.12 \pm 0.14$ & \\
\hline $\mathrm{E}_{\text {dihedrals }}$ & & $0.83 \pm 3.2 \times 10$ & \\
\hline $\mathrm{E}_{v d w}$ & & $-9.48 \pm 0.16$ & \\
\hline $\mathrm{E}_{\text {total }}$ & & $18.06 \pm 0.16$ & \\
\hline
\end{tabular}

Table 1. Summary of structural constraints and structure statistics for a set of 20 structures of $12-\mathrm{HHT}$ in the presence of BLT2 receptor. (In the case where the inter-protons distance indicated is not an integer, this means that magnetically not equivalent protons could not be distinguished in the NOESY spectrum. For instance, between $\mathrm{H} 5$ and $\mathrm{H} 6$, a dipolar interaction with $\mathrm{H} 7$ corresponds to an average inter-proton restraints of 2.5). 

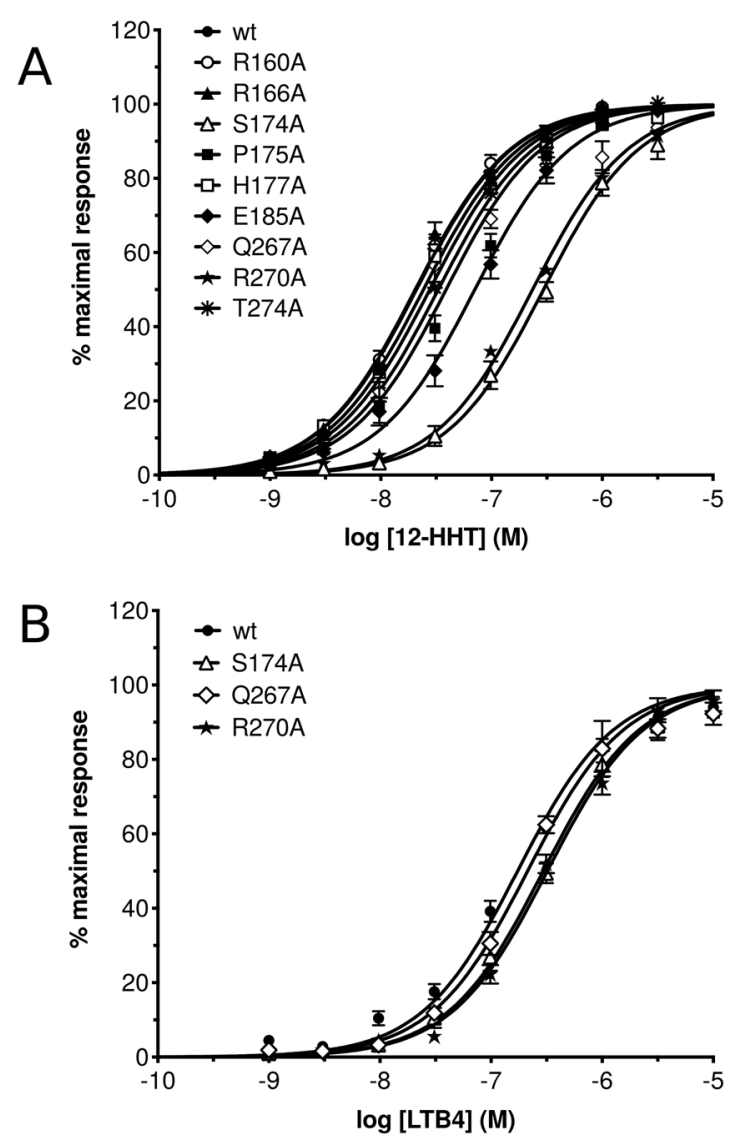

Figure 3. $\mathrm{G}_{i}$ protein activation catalyzed by the wild-type BLT2 receptor and its mutants in the presence of increasing 12-HHT (A) or LTB4 (B) concentrations. Data are presented as the mean \pm SEM of three experiments.

\begin{tabular}{|l|l|l|}
\hline Constructs & LogEC50 & EC50 \\
\hline $\mathrm{wt}$ & -7.677 & $2.102 \times 10^{-8}$ \\
\hline $\mathrm{R} 160^{4.64} \mathrm{~A}$ & -7.689 & $2.046 \times 10^{-8}$ \\
\hline $\mathrm{R} 166^{E C L 2} \mathrm{~A}$ & -7.684 & $2.071 \times 10^{-8}$ \\
\hline $\mathrm{S} 174^{E C L 2} \mathrm{~A}$ & -6.539 & $2.948 \times 10^{-7}$ \\
\hline $\mathrm{P} 175^{E C L 2} \mathrm{~A}$ & -7.410 & $3.889 \times 10^{-8}$ \\
\hline $\mathrm{H} 177^{E C L 2} \mathrm{~A}$ & -7.615 & $2.427 \times 10^{-8}$ \\
\hline $\mathrm{E} 185^{5.42} \mathrm{~A}$ & -7.151 & $7.070 \times 10^{-8}$ \\
\hline $\mathrm{Q} 267^{7.32} \mathrm{~A}$ & -7.481 & $3.307 \times 10^{-8}$ \\
\hline $\mathrm{R} 270^{7.35} \mathrm{~A}$ & -6.629 & $2.350 \times 10^{-7}$ \\
\hline $\mathrm{T} 274^{7.39} \mathrm{~A}$ & -7.557 & $2.771 \times 10^{-8}$ \\
\hline
\end{tabular}

Table 2. EC50 values inferred from $\mathrm{G}_{i}$ protein activation catalyzed by the wild-type BLT2 receptor and its mutants in the presence of $12-\mathrm{HHT}$.

more loosely defined if we take into account an ensemble of 15 or 20 NMR structures (Fig. S9 and see dihedral $\zeta$ in Figure S10). If we try to coincide the lowest energy conformers of LTB4 with the 12-HHT structure ensemble by superimposing the most rigid part of the hydrocarbon skeletons, i.e. carbons 7 to 12 , we find that, globally, the fold of LTB4 is close to the 12-HHT structure in the presence of the same receptor (Fig. 5): the orientation of the carboxyl-end is similar, but not identical, the hydroxyl group in position 12 points towards the same direction despite an opposite chirality of the asymmetric carbon, and the methyl end for both ligands are quite close despite the LTB4 chain containing three more carbons. However, the two chains from carbon 12 -bearing the hydroxyl group - to the methyl end display different orientations (see views 1 and 3 in Fig. 5). This region of these ligands is supposed to be located at the bottom of the pocket of the receptor, based on the grafting of fluorescent probes at the carboxyl-end on the LTB4 for instance that does not affect the binding properties to BLT2 $2^{72}$.

Attempts to get a model of LTB4 associated with BLT2 failed because we could not identify clear mutants that impact significantly on the binding of LTB4 onto BLT2, and this prevented us from getting a reasonable model of 

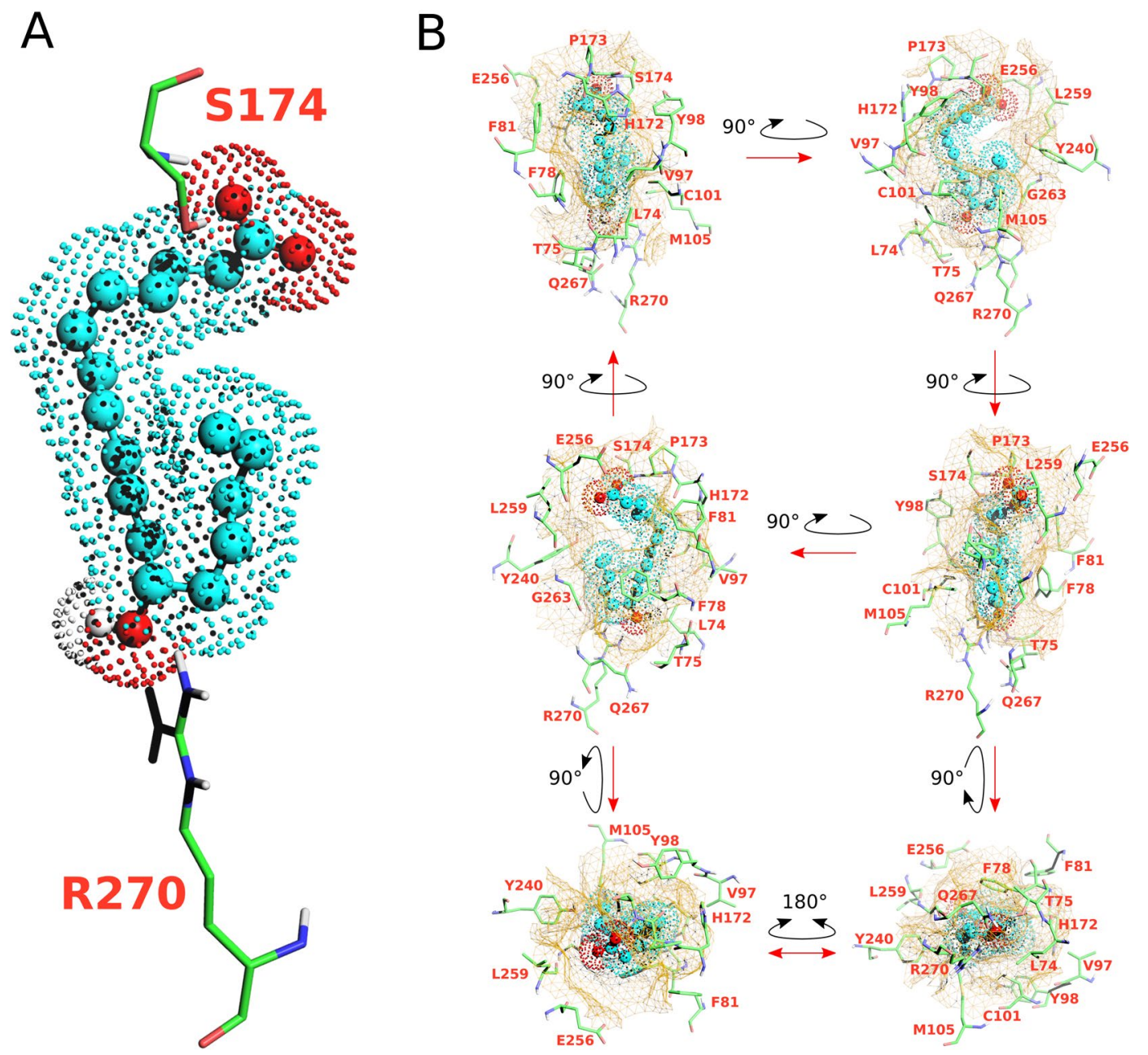

Figure 4. Docking model of the NMR structure of 12-HHT in human BLT2 receptor (see HADDOCK structural statistics in Table S11). (A) represents the ligand in spheres and dots (hydrocarbon skeleton in cyan, oxygen atoms in red and the proton of the hydroxyle group in position $12 \mathrm{in}$ white) double-locked at the top and the bottom of the orthosteric pocket by two hydrogen bonds with S174 and R270 residues. (B) represents six different views of the ligand in the orthosteric pocket of the receptor. The cavity of the ligand binding pocket is represented with a brown mesh surface at a maximum distance of $5 \AA$ from the ligand. Amino acids delineating the pocket are indicated in orange.

the ligand:receptor complex. Furthermore, in contrast to 12-HHT, LTB4 is a very low-affinity ligand for BLT2, and this certainly contributes to the fact that we could not get any satisfying model for this ligand.

\section{Discussion}

Historically BLT2 was designated as the low-affinity LTB4 receptor, in contrast to BLT1, with in cellulo $\mathrm{K}_{d}$ of $\sim 20 \mathrm{nM}$ compared with $\sim 1 \mathrm{nM}$ for BLT1 ${ }^{30}$. More recently, strong evidences led to the discovery of BLT2 endogenous agonist, $12-\mathrm{HHT}^{33,38,41}$, a non-eicosanoid fatty acid compound which essentially comes from the conversion of prostaglandin $\mathrm{H} 2$ to thromboxane A2. In cellulo measurements indicate a higher affinity of 12-HHT for BLT2 compared to LTB4, by about one order of magnitude ${ }^{38}$. This was also observed by in vitro binding measurements of LTB4 and 12-HHT onto a purified BLT2 receptor associated with amphipols in solution, with $\mathrm{K}_{d}$ of $\sim 200$ and $\sim 60 \mathrm{nM}$, respectively ${ }^{19}$. To be noted, the affinity of the isolated receptor for its agonists is lower than that measured in cell systems. However, high affinity can be recovered by associating the isolated receptor with its cognate $\mathrm{G}$ proteins $^{51}$. Hence, the structures obtained here with the isolated BLT2 are likely signatures of the low-affinity, uncoupled state of the receptor. A qualitative comparison of NMR NOESY spectra clearly indicate an organization of both ends of 12-HHT in the presence of BLT2 (Figs. S2 and S3). Structure calculation confirmed that observation and led to a single set of converged structures (Fig. 2). The model proposed herein describes a ligand that is double-locked in the receptor by two hydrogen bonds which are in accordance with single-directed mutagenesis associated with ligand binding experiments (Fig. 3A): one NH. . O hydrogen bond between the $\mathrm{OH}$ moiety of the ligand and $\mathrm{R} 270^{7.35}$ at the bottom of the orthosteric pocket, and a stronger $\mathrm{OH}$. . O hydrogen bond involving the COOH group of $12-\mathrm{HHT}$ with S274 ${ }^{E C L 2}$, i.e. on the opposite side of the ligand pocket (Fig. 4). These two residues are highly conserved in BLT receptors (Fig. S6), but interestingly, while BLT1 is almost activated by 


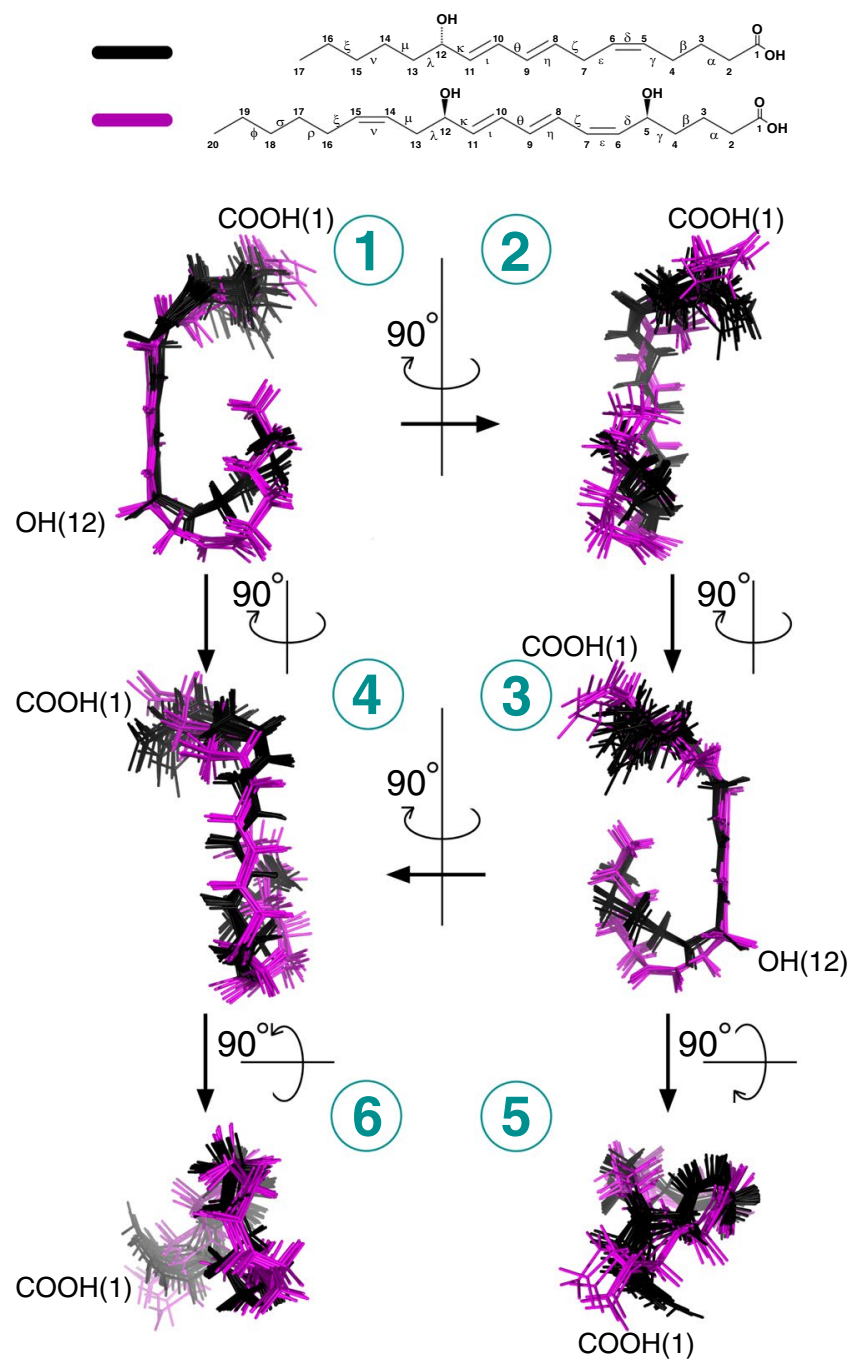

Figure 5. Comparison of 12-HHT and LTB4 3D NMR structures associated with human BLT2. Six different views of superimposed ensembles of 20 energy-minimized conformers of 12-HHT (in black, from Fig. 2), and the 7 lowest energy conformers of LTB4 (in purple, from Fig. S9). On Top are represented the chemical structures of the ligands.

the LTB4 only, and not by 12-HHT, mutation of these two residues does not affect the binding of LTB4 onto BLT2 (Fig. 3B and Table 3). In complement to measurements at equilibrium, in vitro off-rate constant measurements led to a bound time 3.6 times longer for $12-\mathrm{HHT}$ than $\mathrm{LTB}_{4}{ }^{19}$. This also tends to suggest additional short range interactions for 12-HHT compared with LTB4. A tentative superimposition of 12-HHT and LTB4 in their BLT2-bound states described a similar fold, especially if we take into account the 7 lowest energy structures obtained in the converged ensemble of structures of LTB4 (Fig. 5 and Table S10). However, several main features distinguish 12-HHT and LTB4 than could explain these different binding properties: a shorter hydrocarbon chain for 12-HHT, with a double bond less, the absence of a hydroxyl group on position 5 , and an opposite chirality for the asymmetric carbone 12 (see top of Fig. 5). In addition, superimposing the rigid core of these two ligands indicates noticeable differences, especially from the asymmetric carbon 12 to the methyl end (Fig. 5), a region which should interact with the bottom of the orthosteric pocket.

Structures have revealed that a high percentage of identity between sub-families of class A GPCRs can be observed for amino acids sculpting the orthosteric binding pocket in contrast with the extracellular domains and membrane interface, which comprise the $\mathrm{N}$-terminus end and three extracellular loops and the top of the TMs. These regions display a higher diversity in both sequence and length ${ }^{73}$. Experimental data indicate that ECLs are intimately implicated in GPCR activation ${ }^{74}$. Compilation of that information suggests a role of these extracellular regions in GPCR signaling, including ligand binding and selectivity ${ }^{75}$ in addition to ligand efficacy ${ }^{76}$, allosteric modulations, e.g. ${ }^{77}$ and constitutive activation ${ }^{78}$. Our model based on the crystallographic active state of the $\beta 2 \mathrm{AR}$ highlights the importance of ECL2 as a lock above the orthosteric site which one residue, S174, display the strongest interaction above all residues that interact with the ligand. Two additional residues, i.e. H172 and P173, associated with S174 define a hood above the ligand that probably contribute to improve the residence time of the ligand to promote the binding of an intracellular partner as equilibrium binding properties may not totally 


\begin{tabular}{|c|c|c|}
\hline Constructs & LogEC50 & EC50 \\
\hline wt & -7.677 & $2.102 \times 10^{-8}$ \\
\hline $\mathrm{R} 160^{4.64} \mathrm{~A}$ & -7.689 & $2.046 \times 10^{-8}$ \\
\hline $\mathrm{R} 166^{E C L 2} \mathrm{~A}$ & -7.684 & $2.071 \times 10^{-8}$ \\
\hline $\mathrm{S} 174^{E C L 2} \mathrm{~A}$ & -6.539 & $2.948 \times 10^{-7}$ \\
\hline $\mathrm{P} 175^{E C L 2} \mathrm{~A}$ & -7.410 & $3.889 \times 10^{-8}$ \\
\hline $\mathrm{H} 177^{E C L 2} \mathrm{~A}$ & -7.615 & $2.427 \times 10^{-8}$ \\
\hline $\mathrm{E} 185^{5.42} \mathrm{~A}$ & -7.151 & $7.070 \times 10^{-8}$ \\
\hline $\mathrm{Q} 267^{7.32} \mathrm{~A}$ & -7.481 & $3.307 \times 10^{-8}$ \\
\hline $\mathrm{R} 270^{7.35} \mathrm{~A}$ & -6.629 & $2.350 \times 10^{-7}$ \\
\hline $\mathrm{T} 274^{7.39} \mathrm{~A}$ & -7.557 & $2.771 \times 10^{-8}$ \\
\hline
\end{tabular}

Table 3. EC50 values inferred from $\mathrm{G}_{i}$ protein activation catalyzed by the wild-type BLT2 receptor and its mutants in the presence of LTB4.

govern the activation of GPCRs. In other words, non-equilibrium kinetics of the ligand binding event may also play an important role ${ }^{79}$.

The method proposed in this study deserves to be improved as some imperfections could introduce biases in both the structure calculation and also in the model. First of all, the definition of parameter and topology files for organic compounds is not so trivial despite the development of very efficient and convenient programs like PRODRG $^{53}$ and XPLO2D ${ }^{54}$ that have been used in the present study. Structure calculations were based on the program ARIA ${ }^{55}$ associated with $\mathrm{CNS}^{56}$ which contains a full relaxation matrix treatment of NOE data to take into account indirect ${ }^{1} \mathrm{H}-{ }^{1} \mathrm{H}$ cross-relaxation pathways ${ }^{57,58}$ but does not take into account the contribution of the chemical exchange of the ligand from the receptor in the calculation. It would be interesting to include a matrix of exchange to properly gauge the impact of the $k_{\text {off }}$-or conversely the residence time- of the ligand in the structure calculation. In the present study, the receptor is perdeuterated (98\%) in order to limit the spin diffusion into the ligand only, i.e. not relayed by protons of the protein, but the remaining $2 \%$ of protons in the receptor may slightly impact also the intra-ligand dipolar restraints observed by NMR. We also tried to be as cautious as possible to use specific intra-dipolar interactions only in the structure calculations, but this does not exclude some imperfections in the approach. For all these reasons, we cannot exclude that both flexible ends of 12-HHT (carbons 1 to 4 and 13 to 17) may display slightly different orientations compared to the set of structures described herein. It should be noted that in the recent published structure of the protaglandin E2 bound to EP3 receptor ${ }^{80}$, the ligand displays also a non-extended conformation in accordance with our results (Fig. S11). In addition, docking simulations with the set of conformers of free 12-HHT in solution (see Fig. 2) could not reproduce the contacts observed between 12-HHT BLT2-bound structures and S174 and R270 (Fig. S12). However, to help us to improve the method, NOE peak volumes for both 12-HHT and LTB4 are available to the community in Tables S1-S4 and S6-S9, respectively. Ideally, the experimental determination of a high-resolution structure of BLT2 receptor associated with 12-HHT would greatly help to adjust the approach detailed here. Other biophysical methods like NMR chemical shift perturbation experiments with a specifically isotope-labeled BLT2 receptor, crosslinking and/or hydrogen/deuterium exchange associated with mass spectrometry, and also molecular dynamics simulations could help to improve the model proposed in the present study by determining some contact between the ligand and some amino acids of the receptor. These methods have been used in the GPCR field to delineate ligand:receptor contacts ${ }^{81-83}$ and probe the changes in receptor conformation induced by the interaction with the ligands ${ }^{84}$. Overall, our data bring a first description of $12-$ HHT in its receptor-bound state. This demonstrates the interest of a NMR-based approach to provide a description of the structure and dynamics of natural ligands bound to unmodified receptors at physiological temperatures, in complement to X-ray crystallography and cryoEM methods.

Received: 22 October 2019; Accepted: 28 January 2020;

Published online: 14 February 2020

\section{References}

1. Bockaert, J. \& Pin, J. P. Molecular tinkering of G protein-coupled receptors: an evolutionary success. EMBO. J. 18, 1723-1729 (1999).

2. Santos, R. et al. A comprehensive map of molecular drug targets. Nat. Rev. Drug. Discov. 16, 19-34 (2017).

3. Hauser, A. S., Attwood, M. M., Rask-Andersen, M., Schiöth, H. B. \& Gloriam, D. E. Trends in GPCR drug discovery: New agents, targets and indications. Nat. Rev. Drug. Discov. 16, 829-842 (2017).

4. Rasmussen, S. G. et al. Structure of a nanobody-stabilized active state of the $\beta(2)$ adrenoceptor. Nature 469, 175-180 (2011).

5. Ring, A. M. et al. Adrenaline-activated structure of 2-adrenoceptor stabilized by an engineered nanobody. Nature 502, 575-579 (2013).

6. Manglik, A., Kobilka, B. K. \& Steyaert, J. Nanobodies to Study G Protein-Coupled Receptor Structure and Function. Annu. Rev. Pharmacol. Toxicol. 57, 19-37 (2017).

7. Weis, W. I. \& Kobilka, B. K. The Molecular Basis of G Protein-Coupled Receptor Activation. Annu. Rev. Biochem. 87, 897-919 (2018).

8. Erlandson, S. C., McMahon, C. \& Kruse, A. C. Structural Basis for G Protein-Coupled Receptor Signaling. Annu. Rev. Biophys. 47, $1-18(2018)$.

9. Hilger, D., Masureel, M. \& Kobilka, B. K. Structure and dynamics of GPCR signaling complexes. Nat. Struct. Mol. Biol. 25, 4-12 (2018). 
10. Thal, D. M. et al. Recent advances in the determination of G protein-coupled receptor structures. Curr. Opin. Struct. Biol. 51, 28-34 (2018).

11. Casiraghi, M. et al. Functional Modulation of a G Protein-Coupled Receptor Conformational Landscape in a Lipid Bilayer. J. Am. Chem. Soc. 138, 11170-11175 (2016).

12. Casiraghi, M., Banères, J. L. \& Catoire, L. J. NMR Spectroscopy for the Characterization of GPCR Energy Landscapes. In: Topics in Medicinal Chemistry. Springer, Berlin, Heidelberg, pp 1-26 (2017).

13. Casiraghi, M., Damian, M., Lescop, E., Banères, J. L. \& Catoire, L. J. Illuminating the Energy Landscape of GPCRs: The Key Contribution of Solution-State NMR Associated with Escherichia coli as an Expression Host. Biochemistry 57, 2297-2307 (2018).

14. Casiraghi, M. et al. NMR analysis of GPCR conformational landscapes and dynamics. Mol. Cell. Endocrinol. 484, 69-77 (2019).

15. Shimada, I., Ueda, T., Kofuku, Y., Eddy, M. T. \& Wüthrich, K. GPCR drug discovery: integrating solution NMR data with crystal and cryo-EM structures. Nat. Rev. Drug. Discov. 18, 59-82 (2019).

16. Bostock, M. J., Solt, A. S. \& Nietlispach, D. The role of NMR spectroscopy in mapping the conformational landscape of GPCRs. Curr. Opin. Struct. Biol. 57, 145-156 (2019).

17. Inooka, H. et al. Conformation of a peptide ligand bound to its G-protein coupled receptor. Nat. Struct. Biol. 8, 161-165 (2001).

18. Catoire, L. J. et al. Structure of a GPCR ligand in its receptor-bound state: leukotriene B4 adopts a highly constrained conformation when associated to human BLT2. J. Am. Chem. Soc. 132, 9049-9057 (2010).

19. Catoire, L. J., Damian, M., Baaden, M., Guittet, E. \& Banères, J. L. Electrostatically-driven fast association and perdeuteration allow detection of transferred cross-relaxation for $\mathrm{G}$ protein-coupled receptor ligands with equilibrium dissociation constants in the highto-low nanomolar range. J. Biomol. NMR. 50, 191-195 (2011).

20. O'Connor, C. et al. NMR structure and dynamics of the agonist dynorphin peptide bound to the human kappa opioid receptor. Proc. Natl. Acad. Sci. USA 112, 11852-11857 (2015).

21. Yong, K. J. et al. Determinants of Ligand Subtype-Selectivity at 1A-Adrenoceptor Revealed Using Saturation Transfer Difference (STD) NMR. ACS Chem. Biol. 13, 1090-1102 (2018).

22. Brancaccio, D. et al. Ligand-Based NMR Study of C-X-C Chemokine Receptor Type 4 (CXCR4)-Ligand Interactions on Living Cancer Cells. J. Med. Chem. 61, 2910-2923 (2018).

23. Chen, S. et al. Human substance P receptor binding mode of the antagonist drug aprepitant by NMR and crystallography. Nat. Commun. 10, 638 (2019).

24. Bender, B. J. et al. Structural Model of Ghrelin Bound to its G Protein-Coupled Receptor. Structure 27, 537-544 (2019).

25. Ferré, G. et al. Structure and dynamics of GPCR-bound ghrelin reveal the critical role of the octanoyl chain. Proc. Natl. Acad. Sci. USA 116, 17525-17530 (2019).

26. Yokomizo, T., Izumi, T., Chang, K., Takuwa, Y. \& Shimizu, T. A G-protein-coupled receptor for leukotriene B4 that mediates chemotaxis. Nature 387, 620-624 (1997).

27. Kamohara, M. et al. Molecular cloning and characterization of another leukotriene B4 receptor. J. Biol. Chem. 275, 27000-27004 (2000).

28. Tryselius, Y., Nilsson, N. E., Kotarsky, K., Olde, B. \& Owman, C. Cloning and characterization of cDNA encoding a novel human leukotriene B(4) receptor. Biochem. Biophys. Res. Commun. 274, 377-382 (2000).

29. Wang, S. et al. A novel hepatointestinal leukotriene B4 receptor. Cloning and functional characterization. J. Biol. Chem. 275, 40686-40694 (2000).

30. Yokomizo, T., Kato, K., Terawaki, K., Izumi, T. \& Shimizu, T. A second leukotriene B(4) receptor, BLT2. A new therapeutic target in inflammation and immunological disorders. J. Exp. Med. 192, 421-432 (2000).

31. Izumi., T., Yokomizo, T., Obinata, H., Ogasawara, H. \& Shimizu, T. Leukotriene Receptors: Classification, Gene Expression, and Signal Transduction. J. Biochem. 132, 1-6 (2002).

32. Tager, A. M. \& Lustera, A. D. BLT1 and BLT2: the leukotriene B4 receptors. Prostaglandins Leukot. Essent. Fatty Acids 69, 123-134 (2003).

33. Yokomizo, T. Leukotriene B4 receptors: Novel roles in immunological regulations. Adv. Enzyme Regul. 51, 59-64 (2011).

34. Yokomizo, T. Two distinct leukotriene B4 receptors, BLT1 and BLT2. J. Biochem. 157, 65-71 (2015).

35. Borgeat, P. \& Samuelsson, B. Transformation of arachidonic acid by rabbit polymorphonuclear leukocytes. Formation of a novel dihydroxyeicosatetraenoic acid. J. Biol. Chem. 254, 2643-2646 (1979).

36. Yokomizo, T., Kato, K., Hagiya, H., Izumi, T. \& Shimizu, T. Hydroxyeicosanoids bind to and activate the low affinity leukotriene B4 receptor, BLT2. J. Biol. Chem. 276, 12454-12459 (2001).

37. Hamberg, M., Svensson, J. \& Samuelsson, B. Prostaglandin endoperoxides. A new concept concerning the mode of action and release of prostaglandins. Proc. Natl. Acad. Sci. USA 71, 3824-3828 (1974).

38. Okuno, T. et al. 12(S)-Hydroxyheptadeca-5Z, 8E, 10E-trienoic acid is a natural ligand for leukotriene B4 receptor 2. J. Exp. Med. 205, 759-766 (2008).

39. Hecker, M., Haurand, M., Ullrich, V., Diczfalusy, U. \& Hammarström, S. Products, kinetics, and substrate specificity of homogeneous thromboxane synthase from human platelets: development of a novel enzyme assay. Arch. Biochem. Biophys. 254, 124-135 (1987).

40. Goetzl, E. J. \& Gorman, R. R. Chemotactic and chemokinetic stimulation of human eosinophil and neutrophil polymorphonuclear leukocytes by 12-L-hydroxy-5,8,10-heptadecatrienoic acid (HHT). J. Immunol. 120, 526-531 (1978).

41. Iizuka, Y. et al. Protective role of the leukotriene B4 receptor BLT2 in murine inflammatory colitis. FASEB J. 24, 4678-4690 (2010).

42. Matsunaga, Y. et al. Leukotriene B4 receptor BLT2 negatively regulates allergic airway eosinophilia. FASEB J. 27, 3306-3314 (2013).

43. Liu, M. et al. 12-Hydroxyheptadecatrienoic acid promotes epidermal wound healing by accelerating keratinocyte migration via the BLT2 receptor. J. Exp. Med. 211, 1063-1078 (2014).

44. Tong, W. G. et al. Leukotriene B4 receptor antagonist LY293111 inhibits proliferation and induces apoptosis in human pancreatic cancer cells. Clin. Cancer Res. 8, 3232-3242 (2002).

45. Hennig, R. et al. BLT2 is expressed in PanINs, IPMNs, pancreatic cancer and stimulates tumour cell proliferation. Br. J. Cancer 99, 1064-1073 (2008).

46. Lee, J. W. \& Kim, J. H. Activation of the leukotriene B4 receptor 2-reactive oxygen species (BLT2-ROS) cascade following detachment confers anoikis resistance in prostate cancer cells. J. Biol. Chem. 288, 30054-30063 (2013).

47. Houthuijzen, J. M. et al. Lysophospholipids secreted by splenic macrophages induce chemotherapy resistance via interference with the DNA damage response. Nat. Commun. 5, 5275 (2014).

48. van der Velden, D. L. et al. Phase I study of combined indomethacin and platinum-based chemotherapy to reduce platinum-induced fatty acids. Cancer Chemother. Pharmacol. 81, 911-921 (2018).

49. Dahmane, T., Damian, M., Mary, S., Popot, J.-L. \& Banères, J.-L. Amphipol-assisted in vitro folding of G protein-coupled receptors. Biochemistry 48, 6516-6521 (2009).

50. Giusti, F. et al. Synthesis, characterization and applications of a perdeuterated amphipol. J. Membr. Biol. 247, 909-924 (2014).

51. Arcemisbéhère, L. et al. Leukotriene BLT2 receptor monomers activate G(i2) GTP-binding protein more efficiently than dimers. J. Biol. Chem. 285, 6337-6347 (2010).

52. Hwang, T. L. \& Shaka, A. J. Water Suppression That Works. Excitation Sculpting Using Arbitrary Wave-Forms and Pulsed-Field Gradients. J. Magn. Reson. A112, 275-279 (1995).

53. Schüttelkopf, A. W. \& van Aalten, D. M. F. PRODRG: a tool for high-throughput crystallography of protein-ligand complexes. Acta Crystallogr. D60, 1355-1363 (2004). 
54. Kleywegt, G. J. \& Jones, T. A. Model-building and refinement practice. Methods Enzymol. 277, 208-230 (1997).

55. Rieping, W. et al. ARIA2: automated NOE assignment and data integration in NMR structure calculation. Bioinformatics $\mathbf{2 3}$, 381-382 (2007).

56. Brünger, A. T. et al. Crystallography \& NMR system: A new software suite for macromolecular structure determination. Acta Crystallogr., Sect. D: Biol. Crystallogr. 54, 905-921 (1998).

57. Bloembergen, N. On the interaction of nuclear spins in a crystalline lattice. Physica. 15, 386-426 (1949).

58. Linge, J. P., Habeck, M., Rieping, W. \& Nilges, M. Correction of spin diffusion during iterative automated NOE assignment. J. Magn. Reson. 167, 334-342 (2004).

59. Sali, A. \& Blundell, T. L. Comparative protein modelling by satisfaction of spatial restraints. J. Mol. Biol. 234, 779-815 (1993).

60. Fiser, A., Do, R. K. \& Sali, A. Modeling of loops in protein structures. Prot. Sci. 9, 1753-1773 (2000).

61. Marti-Renom, M. A. et al. Comparative protein structure modeling of genes and genomes. Annu. Rev. Biophys. Biomol. Struct. 29, 291-325 (2000)

62. Hori, T. et al. $\mathrm{Na}^{+}$-mimicking ligands stabilize the inactive state of leukotriene B4 receptor BLT1. Nat. Chem. Biol. 14, 262-269 (2018).

63. Zoonens, M., Catoire, L. J., Giusti, F. \& Popot, J. L. NMR study of a membrane protein in detergent-free aqueous solution. Proc. Natl. Acad. Sci. USA 102, 8893-8898 (2005).

64. Banères, J.-L., Popot, J.-L. \& Mouillac, B. New advances in production and functional folding of G-protein-coupled receptors. Trends Biotechnol. 29, 314-322 (2011).

65. Baneres, J.-L. et al. Structure-based analysis of GPCR function: conformational adaptation of both agonist and receptor upon leukotriene B4 binding to recombinant BLT1. J. Mol. Biol. 329, 801-814 (2003).

66. Popot, J.-L. et al. Amphipols from A to Z. Annu. Rev. Biophys. 40, 379-408 (2011).

67. Kumar, A., Ernst, R. R. \& Wüthrich, K. A two-dimensional nuclearOverhauser enhancement (2D NOE) experiment for the elucidation of complete protonproton cross-relaxation networks inbiological macromolecules. Biochem. Biophys. Res. Commun. 95, 1-6 (1980).

68. Wassenaar, T. A. et al. WeNMR: Structural Biology on the Grid. J. Grid. Comp. 10, 743-767 (2012).

69. van Zundert, G. C. P. et al. The HADDOCK2.2 webserver: User-friendly integrative modeling of biomolecular complexes. J. Mol. Biol. 428, 720-725 (2016)

70. Ballesteros, J. A. \& Weinstein, H. Integrated methods for the construction of three-dimensional models and computational probing of structure-function relations in G protein-coupled receptors. Methods Neurosci. 25, 366-428 (1995).

71. Basu, S. et al. Critical role for polar residues in coupling leukotriene B4 binding to signal transduction in BLT1. J. Biol. Chem. 282, 10005-10017 (2007).

72. Sabirsh, A. et al. Fluorescent leukotriene B4: potential applications. J. Lipid Res. 46, 1339-1346 (2005).

73. Wheatley, M. et al. Lifting the lid on GPCRs: the role of extracellular loops. Br. J. Pharmacol. 165, 1688-1703 (2012).

74. Unal, H. \& Karnik, S. S. Domain coupling in GPCRs: the engine for induced conformational changes. Trends Pharmacol. Sci. 33, 79-88 (2012).

75. Peeters, M. C., van Westen, G. J. P., Li, Q. \& IJzerman, A. P. Importance of the extracellular loops in G protein-coupled receptors for ligand recognition and receptor activation. Trends Pharmacol. Sci. 32, 35-42 (2011).

76. Nguyen, A. T. et al. Extracellular Loop 2 of the Adenosine A1 Receptor Has a Key Role in Orthosteric Ligand Affinity and Agonist Efficacy. Mol. Pharmacol. 90, 703-714 (2016).

77. Peeters, M. C. et al. The role of the second and third extracellular loops of the adenosine Al receptor in activation and allosteric modulation. Biochem. Pharmacol. 84, 76-87 (2012).

78. Pantel, J. et al. Loss of constitutive activity of the growth hormone secretagogue receptor in familial short stature. J. Clin. Invest. 116, 760-768 (2006)

79. Gabdoulline, R. R. \& Wade, R. C. Biomolecular diffusional association. Curr. Opin. Struct. Biol. 12, 204-213 (2002).

80. Morimoto, K. et al. Crystal structure of the endogenous agonist-bound prostanoid receptor EP3. Nat. Chem. Biol. 15, 8-10 (2019)

81. Coin, I. et al. Genetically encoded chemical probes in cells reveal the binding path of urocortin-I to CRF class B GPCR. Cell 155, $1258-1269$ (2013).

82. Koole, C. et al. Genetically encoded photocross-linkers determine the biological binding site of exendin- 4 peptide in the N-terminal domain of the intact human glucagon-like peptide-1 receptor (GLP-1R). J. Biol. Chem. 292, 7131-7144 (2017).

83. Schmidt, P. et al. Improved in Vitro Folding of the Y(2) G Protein-Coupled Receptor into Bicelles. Front. Mol. Biosci. 4, 100 (2018).

84. West, G. M. et al. Ligand-dependent perturbation of the conformational ensemble for the GPCR 2 adrenergic receptor revealed by HDX. Structure 19, 1424-1432 (2011).

\section{Acknowledgements}

This work was supported by the Centre National de la Recherche Scientifique (CNRS), Université de Paris and Universités de Montpellier, the Agence Nationale de la Recherche (ANR-17-CE11-0011), Laboratoire d'Excellence (LabEx) DYNAMO (ANR-11-LABX-0011) and Equipements d'Excellence (EQUIPEX) CACSICE (ANR-11EQPX-0008) from the French Ministry of Research. The authors acknowledge access to the biomolecular NMR platform of the IBPC that is supported by the CNRS, the Labex DYNAMO, the Equipex CACSICE and the SESAME Île-de-France.

\section{Author contributions}

F.G. synthetized the perdeuterated amphipol; M.C., E.P., A.P. and L.J.C. performed the production and purification of the receptor; M.D. and J.L.B. performed single mutagenesis experiments and ligand binding assays; F.G. and J.R. characterized the perdeuterated amphipol; C.L.B. managed the NMR spectrometer and K.M. controlled structure calculations; L.J.C. designed and supervised the project, performed the NMR sample preparations and experiments; conducted structure calculations, molecular modeling and docking simulations, and wrote the manuscript with editorial input from all authors.

\section{Competing interests}

The authors declare no competing interests.

\section{Additional information}

Supplementary information is available for this paper at https://doi.org/10.1038/s41598-020-59571-6.

Correspondence and requests for materials should be addressed to L.J.C. 
Reprints and permissions information is available at www.nature.com/reprints.

Publisher's note Springer Nature remains neutral with regard to jurisdictional claims in published maps and institutional affiliations.

(c) (i) Open Access This article is licensed under a Creative Commons Attribution 4.0 International License, which permits use, sharing, adaptation, distribution and reproduction in any medium or format, as long as you give appropriate credit to the original author(s) and the source, provide a link to the Creative Commons license, and indicate if changes were made. The images or other third party material in this article are included in the article's Creative Commons license, unless indicated otherwise in a credit line to the material. If material is not included in the article's Creative Commons license and your intended use is not permitted by statutory regulation or exceeds the permitted use, you will need to obtain permission directly from the copyright holder. To view a copy of this license, visit http://creativecommons.org/licenses/by/4.0/.

(C) The Author(s) 2020 